\title{
L'HOMME L'Homme
}

Revue française d'anthropologie

$180 \mid 2006$

Rendre visible

\section{Marlène Laruelle \& Sébastien Peyrouse, Les Russes du Kazakhstan. Identités nationales et nouveaux États dans l'espace post-soviétique}

Paris, Institut français d'études sur l'Asie centrale - Maisonneuve \& Larose, 2004, 354 p., index, fig., tabl.

\section{Élisabeth Gessat-Anstett}

\section{OpenEdition}

\section{Journals}

Édition électronique

URL : http://journals.openedition.org/lhomme/2581

DOI : 10.4000//homme.2581

ISSN : 1953-8103

Éditeur

Éditions de l'EHESS

Édition imprimée

Date de publication : 1 décembre 2006

Pagination : 234-235

ISSN : 0439-4216

Référence électronique

Élisabeth Gessat-Anstett, « Marlène Laruelle \& Sébastien Peyrouse, Les Russes du Kazakhstan. Identités nationales et nouveaux États dans l'espace post-soviétique », L'Homme [En ligne], 180 | 2006, mis en ligne le 25 octobre 2006, consulté le 24 septembre 2020. URL : http://journals.openedition.org//homme/ 2581 ; DOI : https://doi.org/10.4000//homme.2581

Ce document a été généré automatiquement le 24 septembre 2020.

(C) École des hautes études en sciences sociales 


\section{Marlène Laruelle \& Sébastien} Peyrouse, Les Russes du Kazakhstan. Identités nationales et nouveaux États dans l'espace post-soviétique

Paris, Institut français d'études sur l'Asie centrale - Maisonneuve \& Larose, 2004, 354 p., index, fig., tabl.

\section{Élisabeth Gessat-Anstett}

1 À la SEULE MESURE de l'Asie centrale, la dissolution de l'URSS au début des années 1990 a généré de radicales transformations géopolitiques dont les impacts sociaux et culturels pourtant sans précédents restent peu étudiés. En s'attachant à l'exemplaire complexité offerte par le cas des populations russes du Kazakhstan, Marlène Laruelle et Sébastien Peyrouse nous restituent une étude particulièrement maîtrisée sur la postérité du colonialisme russe et soviétique dans les espaces centrasiatiques.

Leur ouvrage est en effet consacré à la communauté russe du Kazakhstan ${ }^{1}$ et aux changements qui en une quinzaine d'années l'ont vue passer d'une situation de domination (notamment démographique) à une position de dépendance marquée par une importante vulnérabilité. Cette étude, réalisée à partir d'une enquête rendue possible par l'affectation des auteurs pendant près de deux ans à Tachkent (à l'Institut français d'études sur l'Asie centrale), aborde les aspects à la fois politiques, religieux et sociaux des mutations en cours.

Mise en lumière dès les premières pages, la dimension politique des changements vécus par les Russes du Kazakhstan est marquée par le contexte d'accession à l'indépendance d'un pays où l'objectif affiché de consolider un État-nation s'est rapidement traduit dans le milieu des années 1990 par l'émergence d'un pouvoir autoritaire centré sur la personne du président Noursoultan Nazarbaev. Or, le règlement de la question nationale - posée par la cohabitation sur le sol kazakh d'importantes communautés d'origines slaves (Russes, Biélorusses et Ukrainiens) mais aussi allemande, tatare ou ouiggour -, entamé au Kazakhstan sur un mode administratif et folkloriste directement 
hérité du régime soviétique, révèle que les enjeux de la «Kazakhisation » du pays amorcée dès l'accession au pouvoir de Nazarbaev dépassent largement le seul cadre constitutionnel et juridique pour relever effectivement de procédures d'ethnicisation du pouvoir dans des logiques de concentration de l'autorité. Pour les Russes, la question de la citoyenneté, des modalités de son attribution comme de son exercice, focalise donc rapidement l'attention d'une communauté préoccupée par la possibilité de sa disparition et tendue vers la légitimation de son existence sur le sol kazakh.

4 L'intérêt accordé par les deux auteurs, dans la partie centrale de l'ouvrage, à la question religieuse leur permet alors de mettre en lumière l'ancienneté de l'instrumentation des affiliations cultuelles à l'intérieur de processus d'affirmation communautaires qui prennent notamment appui sur des pratiques d'écriture de l'histoire. Dans le Kazakhstan post-soviétique, la maîtrise de l'écriture de l'histoire des communautés, célébrant la légitimité et l'ancienneté de l'ancrage territorial des Églises, revêt ainsi une importance stratégique. Ces productions textuelles et idéologiques semblables dans leurs logiques mais inconciliables dans leur propos, véritables miroirs des discours politiques locaux, que Marlène Laruelle et Sébastien Peyrouse abordent en détail, contribuent dès lors à consolider les différences bien plus qu'à esquisser les fondements et les modalités d'une coexistence des communautés russes et kazakhes. L'exemple offert par les Cosaques du nord du pays met à lui seul en exergue les ressorts sur lesquels prend appui dans ce contexte un propos, plutôt qu'un véritable projet politique, sécessionniste et autonomiste.

5 À travers l'analyse de la portée du dilemme "partir ou rester » qui s'impose de façon ultime à la communauté russe du Kazakhstan, c'est donc bien à une forme de la décolonisation que les deux auteurs nous invitent à réfléchir, tant les régimes de coexistence semblent là aussi difficiles à mettre en place. Leur attention se fixe pour finir sur l'importance des flux migratoires et sur l'impact de cette re-émigration massive vers la Fédération de Russie, dont l'ampleur et la durée (précisément restituée dans une chronologie récapitulative en fin d'ouvrage) marquent désormais profondément la démographie et l'économie du Kazakhstan en général, comme la cohésion de la communauté russe kazakhstanaise en particulier. Le fait que ce départ/ retour représente désormais un horizon indépassable pour les Russes rétifs à leur kazakhisation permet aux auteurs de s'interroger de façon ultime sur les fondements de la production d'une identité "pied-rouge ", proposant par là même une lecture comparative particulièrement stimulante des processus de décolonisation nord-africain et centrasiatique.

6 L'enquête réalisée par Marlène Laruelle et Sébastien Peyrouse, auprès d'une communauté devenue démographiquement minoritaire en moins d'une décennie et marquée par l'expérience d'une identité russe "orientalisée ", restitue ainsi très scrupuleusement à la fois le dynamisme, la radicalité et la congruence des transformations politiques, sociales et culturelles advenues en Asie centrale à l'issue de l'évaporation de l'empire soviétique avec celles intervenues ailleurs dans le monde au cours de la seconde moitié du $\mathrm{xx}^{\mathrm{e}}$ siècle. Ce faisant, cet ouvrage particulièrement clair et documenté permet également d'envisager, notamment dans son dernier chapitre, toute la complexité et l'importance des enjeux géopolitiques et économiques qui président désormais en Russie à la mobilisation et à l'instrumentalisation des communautés russes en diaspora dans l'ancien espace soviétique. 


\section{NOTES}

1.. Les Russes s'y sont installés en différentes vagues de peuplement, depuis l'arrivée des Cosaques au XVIII ${ }^{\mathrm{e}}$ siècle pour les plus anciennes, jusqu'à, pour les plus récentes, la venue des jeunes communistes participant à la campagne de défrichement des terres vierges entamée dans les années 1950, accompagnés de représentants d'une élite technique, scientifique et intellectuelle. 